\title{
Controlled Semisolid Forging of Aluminium Alloys Using Mechanical Servo Press to Manufacture Products with Homo- and Heterogeneous Microstructures
}

\author{
Jun Yanagimoto ${ }^{1}$, Jian-Bo Tan $^{2}$, Sumio Sugiyama ${ }^{1}$ and Yi Meng ${ }^{3, *}$ \\ ${ }^{1}$ Institute of Industrial Science, The University of Tokyo, Tokyo 153-8505, Japan \\ ${ }^{2}$ School of Material Science and Engineering, Hebei University of Science and Technology, Shijiazhuang 050018, China \\ ${ }^{3}$ Graduate School of Engineering, The University of Tokyo, Tokyo 153-8505, Japan
}

Controlled forging of aluminium alloys is conducted using a mechanical servo press. Semisolid forging can reduce the number of forging passes and energy consumption to produce a product with suitable microstructure. In the proposed semisolid forging, solid fraction of the aluminium alloys being forged is controlled to enable the manufacture of products with homogeneous and heterogeneous microstructures. Semisolid forging experiments using a predetermined sequence represented by transient changes in stroke were systematically conducted. The relationship between the time-dependent semisolid forging sequence and product quality was discussed to reveal the semisolid forming condition for manufacturing products with homogeneous and heterogeneous microstructures. [doi:10.2320/matertrans.M2013098]

(Received March 13, 2013; Accepted April 19, 2013; Published June 25, 2013)

Keywords: forging, aluminium, energy efficiency, microstructure, servo press

\section{Introduction}

A short process chain in metal forming is one of the essential environmental requirements such as less energy consumption. One of the solutions is the use of semisolid forming technology, which falls between casting and hot forming.

As can be seen in a review in CIRP annals, semisolid forming technology has various superior characteristics for establishing a short process chain. ${ }^{1)}$ In addition, semisolid forming or processing enables the control of microstructure through globularization and plastic flow control in the semisolid state, such as recrystallization and partial melting (RAP). The best combination of the above two characteristics, namely, short process chain and wide range of capability in product property control, is a large field of research and development, as was demonstrated in the tool steel production process. ${ }^{2)}$ Several investigations have been carried out in response to the above demand in ferrous and nonferrous alloys. Alloys prepared by RAP or other fabrication methods contain a nondendritic microstructure with adjustable morphology $y^{3)}$ and even exhibit adjustable fluidity and formability in the semisolid state. ${ }^{4)}$ The formability of both ferrous and nonferrous alloys in the semisolid state has been investigated by researchers. ${ }^{5,6)}$ Both ferrous and nonferrous alloy billets with a fine-grained spherical microstructure can be made into complex-geometry products without macrodefects by semisolid forming. ${ }^{7,8)}$ With an optimized heat treatment schedule, the mechanical properties of semisolid processed ferrous and nonferrous alloys are improved and close to those of conventional hotworked ones..$^{9,10)}$

Promising aspects in semisolid forming and processing have been shown by the above investigation. However, it could also be deduced that the control of transient change in the deformation rate and temperature is important to form sound products.

*Graduate Student, The University of Tokyo
The mechanical servo press is rapidly expanding its range of application from cold sheet forming to bulk forming process ${ }^{11)}$ the application of the servo press in semisolid forging was attempted by Azpilgain et al. ${ }^{12)}$ Its motion could be controlled easily so that the use of this free motion capability of the mechanical servo press may promote the control of transient change in the deformation rate and temperature, which dominates fluidity and the liquid fraction to form the product with homogeneous and heterogeneous microstructures within one press machine. With the aim of establishing a short process chain and a wide range of control of microstructures in bulk forming, we investigate semisolid forming, which encompasses all stages from the melt to the solid product in a compact process using one furnace, one mechanical stirrer and one free-motion mechanical servo press, as shown in Fig. 1, taking cast aluminium alloy AC4C and wrought aluminium alloy A6061 as examples. This process can form the product quality better than casting, and the process is quite short compared to forging. The process window of the above compact process required for forming a homogeneous microstructure is shown experimentally, but a heterogeneous microstructure could be intentionally formed if we select forming conditions that could be realized using the mechanical servo press.

\section{Experiment}

\subsection{Materials}

Two types of aluminium alloys are used in the experiment: AC4C for casting and wrought alloy A6061, with the chemical compositions shown in Table 1. The measured semisolid temperature range is shown in Fig. 2. The semisolid temperature range of A6061 is between $838 \mathrm{~K}\left(565^{\circ} \mathrm{C}\right)$ and $925 \mathrm{~K}\left(652^{\circ} \mathrm{C}\right)$, and it is twice as broad as that of AC4C. This broad semisolid temperature range enables a wide forming condition range, as shown below, although wrought alloy A6061 is considered unsuitable for semisolid forming, which has aspects similar to casting owing to the existence of the liquid phase. The solid fraction at the representative 


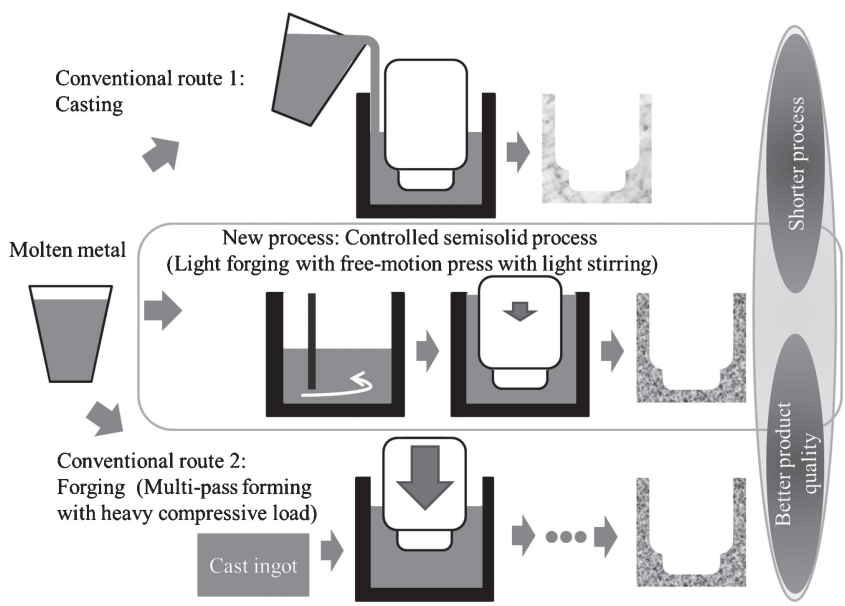

Fig. 1 Schematic illustration of the controlled semisolid process (light forging with free-motion press with light stirring).

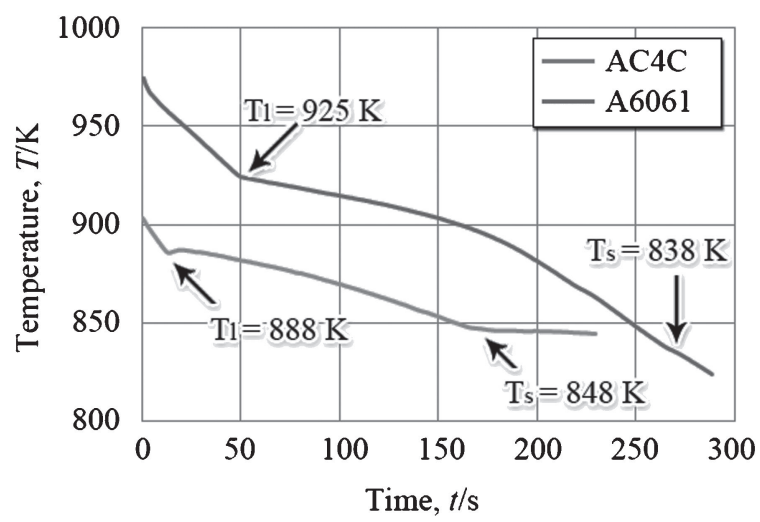

Fig. 2 Measured cooling curve of AC4C and A6061 alloys, T1 is Liquidus temperature, Ts is solidus temperature.

Table 1 Chemical composition of aluminium alloys used in experiments (mass\%).

\begin{tabular}{|c|c|c|c|c|c|c|c|c|c|c|c|c|}
\hline Material & $\mathrm{Si}$ & $\mathrm{Fe}$ & $\mathrm{Cu}$ & $\mathrm{Mn}$ & $\mathrm{Mg}$ & $\mathrm{Zn}$ & $\mathrm{Ni}$ & $\mathrm{Ti}$ & $\mathrm{Pb}$ & $\mathrm{Sn}$ & $\mathrm{Cr}$ & $\mathrm{Al}$ \\
\hline $\mathrm{AC} 4 \mathrm{C}$ & $6.5-7.5$ & $\leqq 0.55$ & $\leqq 0.25$ & $\leqq 0.35$ & $0.25-0.45$ & $\leqq 0.35$ & $\leqq 0.10$ & 0.2 & $\leqq 0.10$ & $\leqq 0.05$ & $\leqq 0.10$ & Bal. \\
\hline A6061 & $0.4-0.8$ & $\leqq 0.7$ & $0.15-0.4$ & $\leqq 0.15$ & $0.8-1.2$ & $\leqq 0.25$ & - & $\leqq 0.15$ & - & - & $0.04-0.35$ & Bal. \\
\hline
\end{tabular}
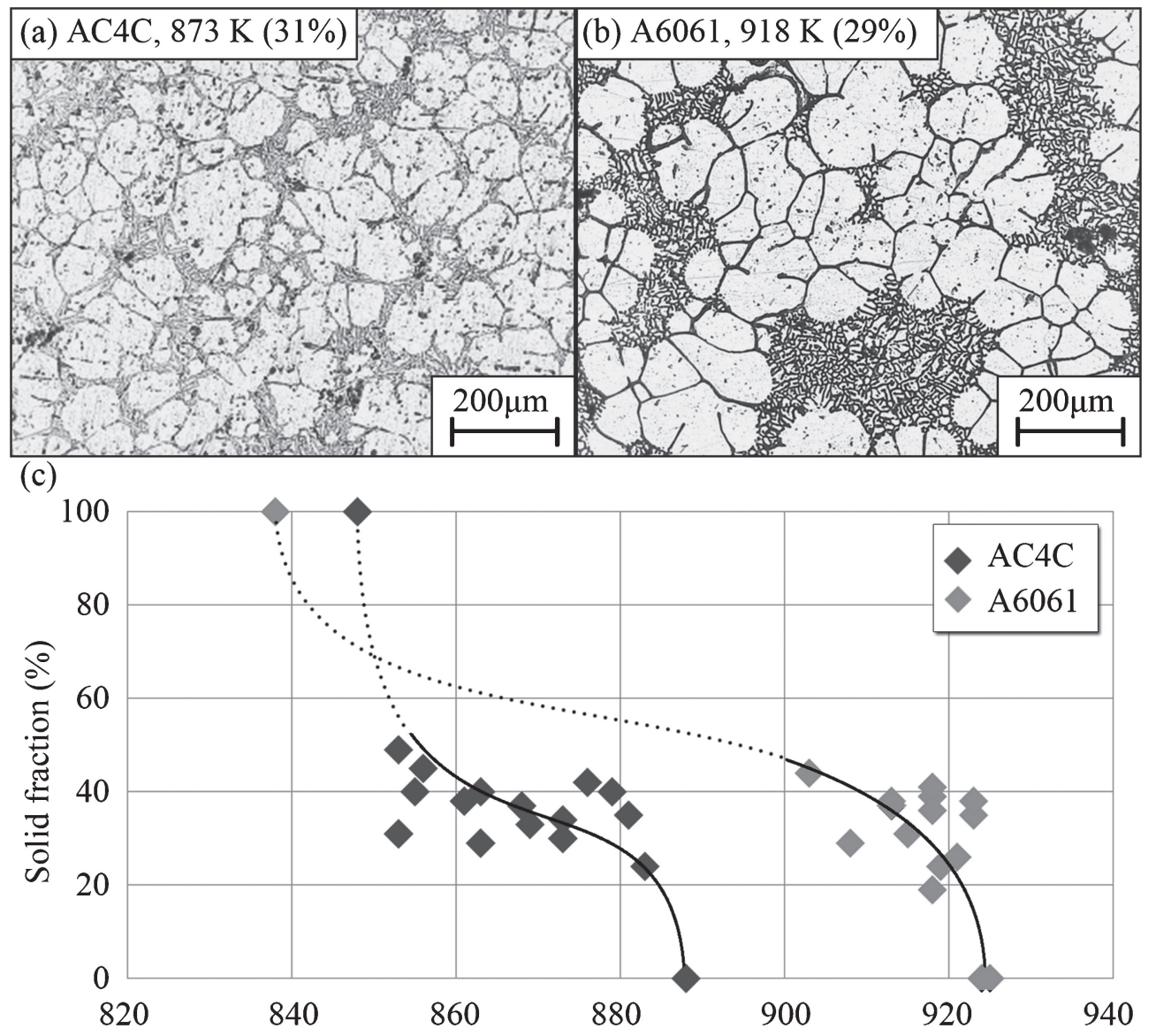

Temperature, $T / \mathrm{K}$

Fig. 3 Relationship of sold fraction and temperature of tested materials.

semisolid temperature after mechanical stirring obtained using an optical microscope and an image analyzer is shown in Fig. 3. A typical characteristic of both alloys is the rapid increase in the solid fraction just below the melting point, which suggests that semisolid forming at a high semisolid temperature is promising for those alloys. ${ }^{13)}$ 

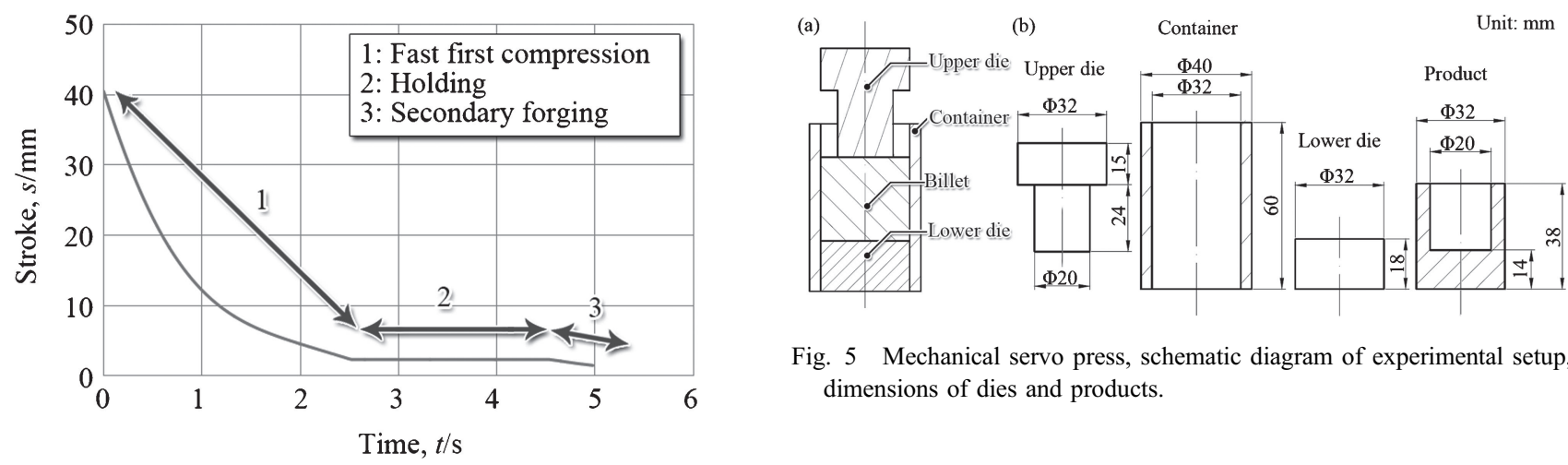

Fig. 5 Mechanical servo press, schematic diagram of experimental setup, dimensions of dies and products.

Fig. 4 Example of a mechanical servo press motion.

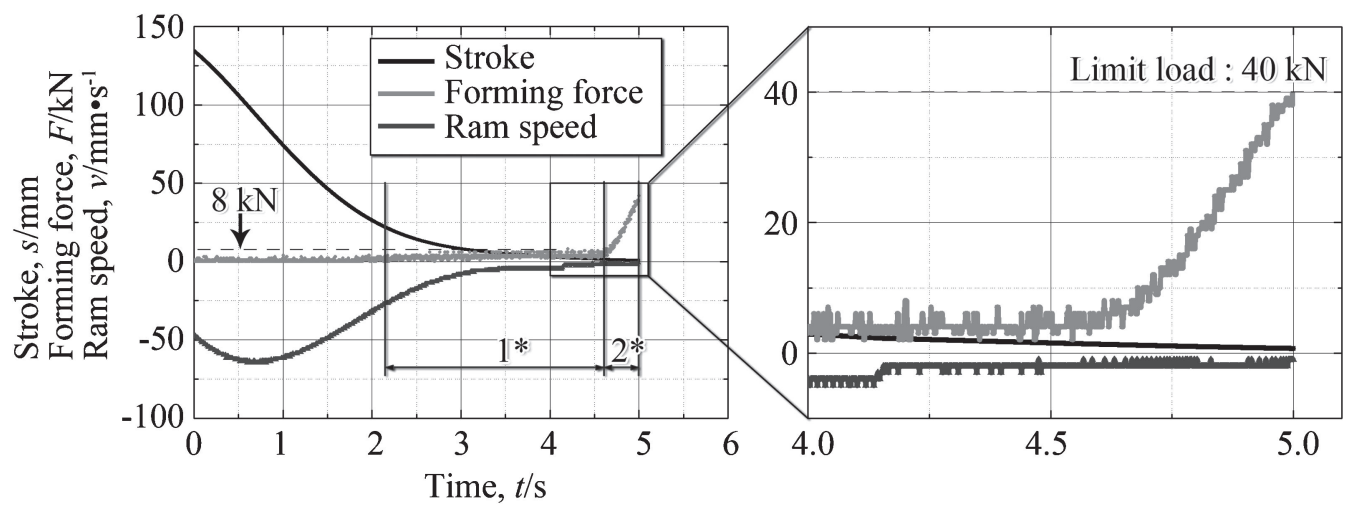

Fig. 6 Time versus stroke, ram speed forming force diagram.

\subsection{Experimental apparatus}

The experimental apparatus is composed of one furnace, one mechanical stirrer and one mechanical servo press. Mechanical stirring is conducted during cooling, to form a semisolid billet with an initial globular microstructure. The main part of this compact process is the use of the mechanical servo press, by which the transient change in the deformation rate and temperature, which dominate the fluidity and liquid fraction, can be controlled, using the free motion capability of the machine, to form products with homo- and heterogeneous microstructures. Many forming sequences could be tested using the compact process shown in Fig. 1, but in the basic step of investigations, the simplest motion of the servo press is used, that is, a combination of fast first compression, short holding time, and slow secondary compression (forging), as shown in Fig. 4. Fast compression is aimed at die-filling of the semisolid metal, short holding time is aimed at controlling the solid fraction of the semisolid metal, and the final forging is the forming step. The final forming step in the semisolid state may produce products with a homogeneous microstructure as well as a heterogeneous microstructure. Solid-fraction control during the proposed compact semisolid forming process may not be easy, but it is important to note that the proposed forming process allows us to form a product with a homogeneous microstructure or a heterogeneous microstructure through precise control of the forming conditions.

The experimental conditions are summarized in Table 2. The solid fraction of aluminum alloy was controlled by controlling the starting temperature of billet. The die setup is schematically illustrated in Fig. 5. Here, simple backward
Table 2 Experimental conditions for semisolid forging using mechanical servo press.

\begin{tabular}{ll}
\hline Semisolid temperature range $(\mathrm{K})$ & $848-888$ (AC4C) \\
$838-925(\mathrm{~A} 6061)$
\end{tabular}

extrusion is adopted. As no lubricant is used, adhesion of aluminum alloy would occur on the die surface. The surface of die should be polished after every experiment. A diagram of time versus stroke, ram speed, temperature, and forming force is shown in Fig. 6. Forming force during the fast first compression is about $8 \mathrm{kN}$, but increases to $40 \mathrm{kN}$ rapidly during secondary (final) forging. The lower forming force during the fast first compression is attributed to the excellent fluidity of semi-solid slurry with low solid fraction. The rapid increase of forming force during the secondary forging is owing to the plastic deformation of solid particles as well as the increase in the solid fraction. The experimental conditions were determined having limited forged load of $40 \mathrm{kN}$, in order to avoid the damage of the container as a precondition. This forging load corresponds to the upper die pressure of about $49 \mathrm{MPa}$. 


\section{Experimental Results}

\subsection{Defect formation under unsuitable forming condi- tions}

The effects of the semisolid forging temperature and upper die temperature on the formation of the underfilled defect, internal cracks and pores of the product were investigated to realize controlled semisolid forging of AC4C and A6061 aluminium alloys using the mechanical servo press. The experimental results are summarized in Fig. 7.

The forging temperature or solid fraction has a significant effect on filling or underfilling in the die for both AC4C and A6061 alloy. Concerning the billet temperature, $852 \mathrm{~K}$, at which the solid fraction is $50 \%$, is the threshold value to split filling or underfilling in the die for AC4C. For the A6061 alloy, $836 \mathrm{~K}$, at which the solid fraction is $30 \%$, is the threshold value. The temperature of the upper die and the holding time affect the temperature drop of the material during semisolid processing. When the temperature drop of the material is large, pores and underfilling defects were generated in the product. The number in Fig. 7 indicates the holding time under the condition when holding time has the significant effects on the formation of defects. When the holding time exceeds $8 \mathrm{~s}$, defects were formed in every test piece even when the upper die temperature was about $600 \mathrm{~K}$. The formation of defects results from the insufficient compressive force that does not reach the minimum required limit load of $40 \mathrm{kN}$ in the secondary forging. The temperature drop during the holding of the material just after the fast first compression is the cause of the elevation of the forging load, because the upper die touches the material during holding. A process window does not open at lower upper die temperature because A6061 is a wrought alloy with less fluidity at semisolid state.

Figure 8 shows the pores in a longitudinal section of the product for various holding times of the upper die. The material is $\mathrm{AC} 4 \mathrm{C}$, and the billet temperature is $853 \mathrm{~K}$ (solid fraction of $49 \%$ ) and the upper die is not preheated. The defect, or pores, can be observed in the product when the holding time is $8 \mathrm{~s}$. In contrast, sound products are produced when the holding time is $1 \mathrm{~s}$ by the proposed semisolid process, which is composed of fast first compression, holding and secondary forging.

The defects can be caused by following two reasons. When the holding time is very short, the temperature of the billet just before secondary forging, which is affected by the upper die temperature and the holding time, is very high and much liquid phase remains in the grain boundary of the solid phase. In this case, the forging load is insufficient in the secondary forging. Thus, the defect occurred in the AC4C product with a holding time of $0 \mathrm{~s}$, when the billet temperature was $863 \mathrm{~K}$, the solid fraction was $40 \%$ and the upper die temperature is $676 \mathrm{~K}$. The second cause of the defect is an insufficient plastic deformation in secondary forging which resulted from higher resistance to deformation of the billet by the chilling effect of the upper die. This defect is dominant in wrought A6061 alloy, as shown in the right of Fig. 7.

A wider process window for manufacturing sound products can be seen for $\mathrm{AC} 4 \mathrm{C}$, such as in the billet temperature or holding time, and upper die temperature, than for A6061, as shown in Fig. 7. This results from the good fluidity and wettability of the liquid phase with a $\mathrm{Si}$ content of approximately $7 \%$, which is typical for a light metal for casting such as $\mathrm{AC} 4 \mathrm{C}$.

\subsection{Homogeneous or heterogeneous distributions of microstructure and properties}

In the preceding paragraph, the effect of manufacturing conditions on defects such as pores and cracks, and filling and underfilling of the product was examined. The homogenization degree of homogenization of the internal structure of the product is examined in this section. Figure 9 shows an example of the measurement of the homogenization degree for two samples from among the A6061 alloys manufactured by the proposed semisolid process. The homogenization degree is defined as the proportion that in the solid-phase area occupies within the entire section. The liquid-phase solidification area is enclosed by a red line in the photograph. The solidified liquid-phase tends to remain at the top and inside of the wall. The homogenization degree of sample A with a billet temperature of $913 \mathrm{~K}$, solid fraction of $33 \%$, upper die temperature of $485 \mathrm{~K}$, and holding time of $0 \mathrm{~s}$ is $86 \%$, which is shown in the left of Fig. 9, while it is $97 \%$ in sample B, for which the billet temperature is $918 \mathrm{~K}$, the solid fraction is $29 \%$, the upper die temperature is $573 \mathrm{~K}$, and the holding time is $0 \mathrm{~s}$.

The measured homogenization degrees of $\mathrm{AC} 4 \mathrm{C}$ and A6061 products under various experimental conditions are summarized in Fig. 10. Detailed measurement has been made in the process windows shown in Fig. 7 to form the product without defect, such as upper die temperature ranging from 483 to $683 \mathrm{~K}$ and holding time ranging from 0 to $4 \mathrm{~s}$. It is found that the homogenization degree tends to decrease when the solid fraction is low in the secondary forging. This phenomenon is attributed to the excessive amount of liquid phase, and could be adjusted by controlling 'Step 2', which will be described as follows. It is worth noting that the sound product with a homogenization degree above $90 \%$ can be manufactured from the liquid by the short and one-shot process comprising mechanical stirring, and fast first compression, holding and secondary forging, utilizing the free-motion ability of the mechanical servo press.

\subsection{Formation mechanism of internal microstructure by proposed process}

According to the experimental results shown in Figs. 7 and 10 , microstructure evolution and deformation behaviors that reveal the tactics for manufacturing a homogeneous product are surmised as three steps, as illustrated in Fig. 11.

'Step 1' is the formation of a homogeneous semisolid alloy slurry that fills the cavity of the forging die during the fast first compression. During this step, the solid particles or grains should flow in a liquid matrix without any aggregation. Once the solid particles aggregate to form the solid network, the liquid phase and solid phase cannot fill the cavity simultaneously: thus, the liquid phase would flow faster and permeate, resulting in phase segregation. From the above viewpoint, to obtain the optimal discrete semi-solid 

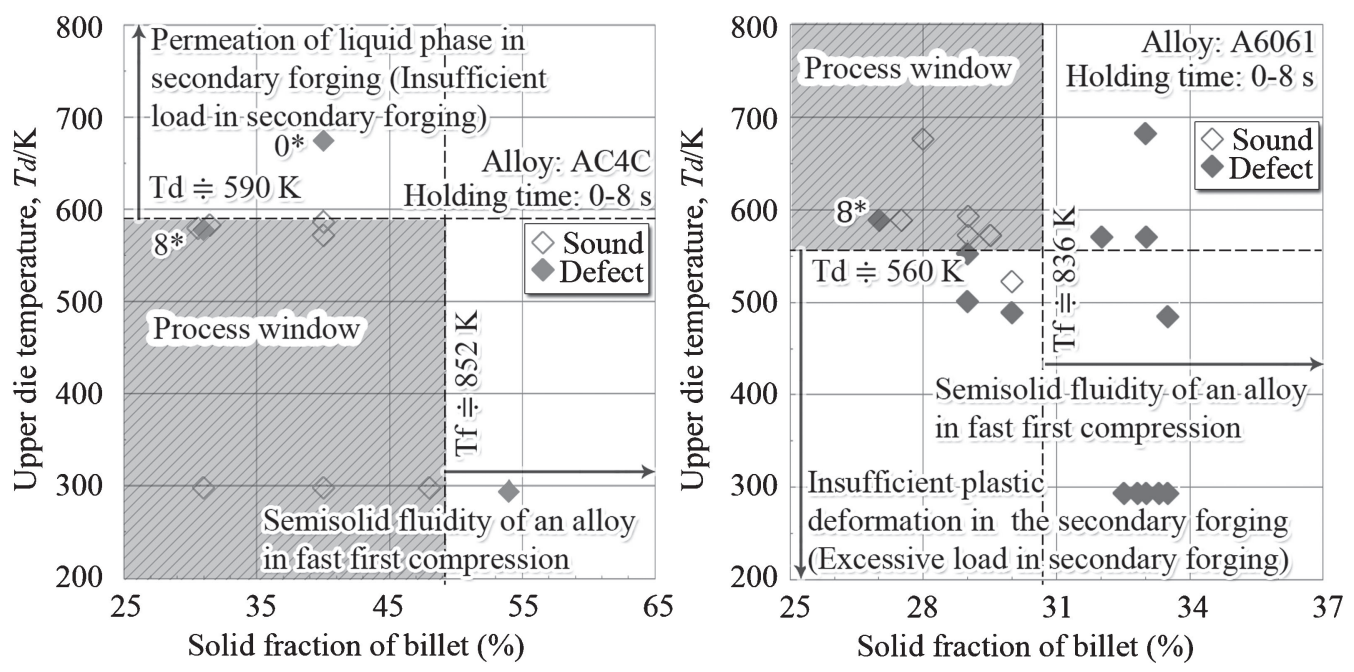

Fig. 7 Process windows in proposed semisolid forming.

(a) Holding time $=8 \mathrm{~s}$

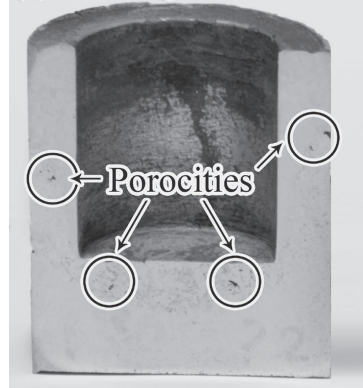

Fig. 8 Inner defects of AC4C semisolid forging products. Forming temperature is $853 \mathrm{~K}(49 \%)$, die temperature is room temperature.
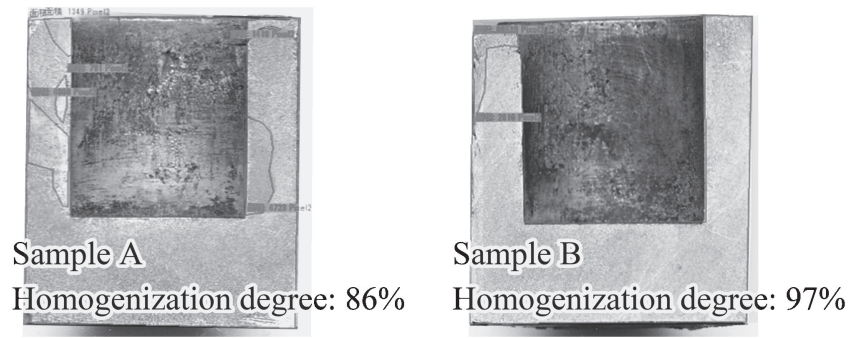

Fig. 9 The example of measuring the homogenizing degree.

ally slurry, the solid fractions of AC4C and A6061 alloy slurries should be less than 50 and $30 \%$, respectively, as shown in Fig. 7.

'Step 2' is the partial solidification stage after the semisolid alloy slurry filled the cavity in 'step 1'. In this stage, a solid phase network will be formed, but there is a certain amount of liquid phase, such as $20-30 \%$, remaining on the grain boundaries of solid particles, and the liquid phase is almost confined in the aggregated solid-phase network. This process is affected by the punch temperature and holding time. The holding times for AC4C and A6061 alloy slurries should be a few seconds depending on the punch temperature, as explained in Section 3.1.

'Step 3' is the secondary forging in the semisolid state to form the final product. The forging load is limited owing to

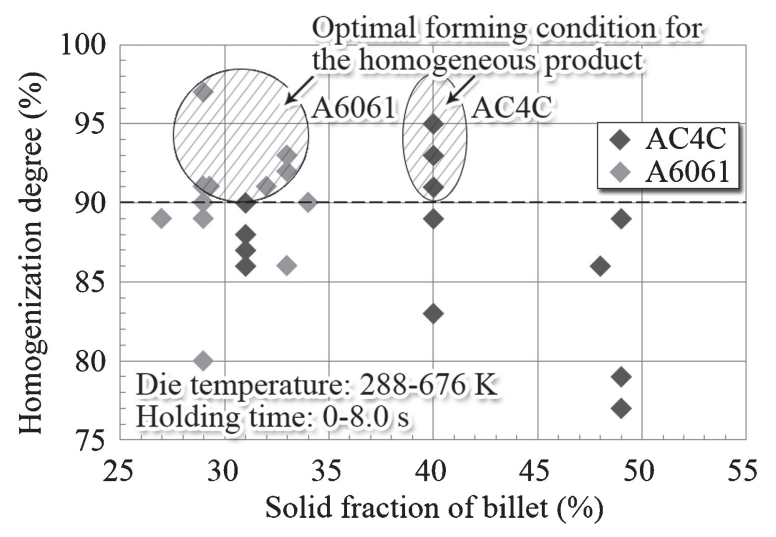

Fig. 10 Optimum semisolid forming conditions in terms of homogenizing degrees.

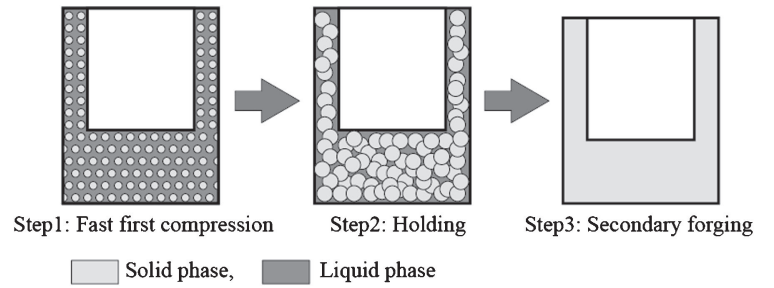

Fig. 11 Schematic illustration on the formation of homo- and heterogeneous microstructure.

the die strength at high temperature. Thus, the fluidity should be maintained to keep the low forging load, but an excessive liquid phase will cause excessive heterogeneity of the product. If the liquid phase is confined inside the solid-phase network, phase segregation is negligible. The liquid phase located at the grain boundaries of solid particles plays the role of lubricant in the second motion and reduces the forming load. The plastic deformation caused by the secondary forging can eliminate the defects occurrence during first fast compression such as porosities. If the production was carried out on much more powerful press machine with stronger die, the quality of products would be even better. 


\section{Conclusion}

A one-shot semisolid forming process starting from molten aluminium alloy to form the product is proposed, utilizing the free-motion capability of the servo press. This process comprises mechanical stirring, and fast first compression, holding and secondary forging, utilizing the free-motion ability of the mechanical servo press. With the aim of determining the acceptable process window of the proposed semisolid process, the effects of forming temperature, punch preheating temperature, and holding time between the fast first compression and secondary forging on the internal structure of aluminium alloy parts were investigated experimentally. The possibility of the production of highquality aluminium alloy parts by controlled semisolid forging with a short process chain by using a servo press was clarified. The results were summarized as the process window in Fig. 7 and the optimum forming condition to obtain the homogeneous product shown in Fig. 10.

\section{Acknowledgments}

This study was financially supported by a Grant-in-Aid for Scientific Research on Innovative Area, "Bulk Nanostructured Metals", through MEXT, Japan (contract No. 22102005).

\section{REFERENCES}

1) M. Kiuchi and R. Kopp: CIRP Ann. 51 (2002) 653-670.

2) Y. Meng, S. Sugiyama, M. Soltanpour and J. Yanagimoto: J. Mater. Process. Technol. 213 (2013) 426-433.

3) H. Atkinson and D. Liu: Mater. Sci. Eng. A 496 (2008) 439-446.

4) M. Kiuchi, J. Yanagimoto and H. Yokobayashi: CIRP Ann. 50 (2001) 157-160.

5) D. Liu, H. Atkinson, P. Kapranos, W. Jirattiticharoean and H. Jones: Mater. Sci. Eng A 361 (2003) 213-224.

6) M. Omar, E. Palmiere, A. Howe, H. Atkinson and P. Kapranos: Mater. Sci. Eng. A 395 (2005) 53-61.

7) P. Kapranos, D. Kirkwood, H. Atkinson, J. Rheinlander, J. Bentzen, P. Toft, C. Debel, G. Laslaz, L. Maenner, S. Blais, J. Rodriguez-Ibabe, L. Lasa, P. Giordano, G. Chiarmetta and A. Giese: J. Mater. Process. Technol. 135 (2003) 271-277.

8) W. Püttgen, W. Bleck, I. Seidl, R. Kopp and C. Bertrand: Adv. Eng. Mater. 7 (2005) 726-735.

9) S. Chayong, H. Atkinson and P. Kapranos: Mater. Sci. Eng. A 390 (2005) 3-12.

10) D. Uhlenhaut, J. Kradolfer, W. Püttgen, J. Loffler and P. Uggowitzer: Acta Mater. 54 (2006) 2727-2734.

11) K. Osakada, K. Mori, T. Altan and P. Groche: CIRP Ann. 60 (2011) $651-672$.

12) Z. Azpilgain, R. Ortubay, A. Blanco and I. Hurtado: Solid State Phenomena 141-143 (2008) 261-266.

13) W. Püttgen, W. Bleck, G. Hirt and H. Shimahara: Adv. Eng. Mater. 9 (2007) 231-245 